\title{
LA INFANCIA EN UN MUNDO DESBOCADO
}

\section{JORGE HURTADO}

Departamento de Sociología II, Psicología, Comunicación y Didáctica. Universidad de Alicante.

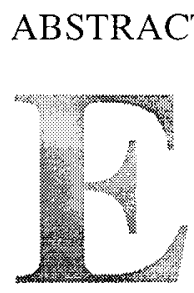

1 artículo repasa las investigaciones recientes sobre el estado de la infancia, a escala global y en los países desarrollados, como indicadores relevantes para medir el progreso y para hacer un balance de la civilización capitalista. A la luz de los datos ofrecidos por instituciones oficiales y de gobierno mundial el arqueo no es alentador. Desde el punto de vista de la situación de la infancia -un indicador privilegiado en la medida en que es previa a cualquier mérito o logro personal- la civilización capitalista es tan bárbara como cualquier otra civilización o sistema social anterior, si no más considerando su superioridad técnica y productiva.

\section{UN MUNDO DESBOCADO}

Nuestra época, dice Giddens en un reciente libro, surgió bajo el impacto de la ciencia, la tecnología y el pensamiento racional, forjado por la Ilustración, «por los libros de pensadores que luchaban contra la influencia de la religión y el dogma, que querían reemplazar por un enfoque más razonado de la vida práctica» (Giddens, 2000: 13). Liberados de los hábitos y prejuicios del pasado, y armados con la posibilidad de una comprensión racional de nosotros mismos y del mundo, el entendimiento de la historia debería haber hecho más fácil su manejo; y el ulterior desarrollo de la ciencia y la tecnología haber facilitado una vida más segura y predecible, un mundo más estable y ordenado. Paradójicamente, sin embargo, en lugar de estar cada vez más bajo nuestro control, el mundo parece fuera de él, un mundo desbocado, y «algunas de las tendencias que se suponía harían la vida más segura y predecible para nosotros, incluido el progreso de la ciencia y la tecnología, tienen a menudo el efecto contrario» (Ibíd.: 14), como es el caso de los impactos medioambientales o de las imponderables modificaciones genéticas. Más aún, la incertidumbre y el riesgo -una categoría que no 
existe en las sociedades tradicionales, poco orientadas al futuro- no sólo son hoy superiores a los de tiempos anteriores sino que afectan a todo el mundo y, lo que es más significativo, provienen de peligros creados por nosotros mismos, son riesgos no externos sino manufacturados (Giddens, 2000: 39; Beck, 1998a).

¿Cómo ha podido prevalecer esta evolución al mismo tiempo fatal e inesperada? Tiene que ver, desde luego, con la expansión de esa civilización, de esa cultura codificada por la Ilustración que consagró el triunfo intelectual de la ciencia racional y experimental, es decir, de la búsqueda de la verdad como algo separado de la indagación sobre lo bueno y lo bello (Wallerstein, 1997). Esa civilización, además, como es sabido, se expandió en tres grandes oleadas entre 1450 y 1900 hasta abarcar todo el mundo, un proceso de larga duración que hoy se denomina globalización, el mantra, la invocación ritual que, al decir de Castañeda, domina nuestra época (Castañeda, 2000).

El término civilización, sin embargo, como recuerda Wallerstein en su balance de la «civilización capitalista» (Wallerstein, ibíd.: 19-40), tiene al menos dos significados. En plural, una civilización designa un conjunto de costumbres, una visión del mundo, una estructura y una cultura (tanto popular, material como de elite) que conforma un todo histórico y que coexiste con otras civilizaciones. Su uso en plural hace referencia, así, a una noción de civilización como particularidad en contraste con otras estructuras y culturas.

En singular, en cambio, como proceso civilizatorio opuesto a la barbarie, el término es ciertamente hijo de la Ilustración. Reflejaba, como bien señala Giddens, el triunfo intelectual de la ciencia racional y experimental, y es concomitante a la idea de un progreso continuo en la condición humana y social, no importa cómo se conceptúe exactamente. Para algunos, en efecto, civilización es sinónimo de modernidad, de éxito económico basado en los avances técnicos y en las mejoras constantes de productividad, que avalan la creencia histórica en el desarrollo y en la posibilidad del progreso. Buena parte de las teorías convencionales sobre el desarrollo sostienen esa fe modernizadora y, frecuentemente, transitiva (Tortosa, 2000). Es decir, la subyacente interpretación whig de la historia a la que se refiere perplejamente Giddens, según la cual el presente es el mejor de los tiempos y el pasado debía desembocar inevitablemente en el presente, ha servido no sólo para analizar y describir, sino también para prescribir: «El progreso no sólo se asumió y analizó, también se impuso» (Wallerstein, 2000: 106), convirtiéndose así en motor de todas las ciencias sociales aplicadas cuya pretensión era, según la vieja fórmula comteana, «savoir pour prévoir et prévoir pour pouvoir». 
Para otros, sin embargo, el desarrollo económico tout court no basta para definir esa civilización en singular, cuya exclusiva occidental se ve hoy amenazada por el desarrollo de los «blancos honorarios» asiáticos. Se requiere, además, el triunfo del individualismo y de los valores fríos frente a las instancias colectivas, recíprocas o redistributivas, la extensión de los derechos como derechos humanos individuales, o la mejora de los comportamientos sociales, la circunscripción de la violencia legítima. Es decir, del conjunto de valores que la civilización occidental ha sancionado como legítimos y que conforman las base del universalismo, al mismo tiempo una visión del mundo y una epistemología (Wallerstein, 1988).

Por supuesto, desde sus orígenes, el universalismo y la idea de progreso fue objeto de feroces críticas teóricas y prácticas. Entre las segundas, el nacionalismo y lo que hoy conocemos como reacciones/regresiones identitarias, cuya cíclica combustión parece guardar relación con los ciclos económicos y con las luchas por la hegemonía (Tortosa, ibíd.), pero también con los momentos de expansión impetuosa del universalismo/globalismo y, en los últimos tiempos, con el derrumbe de las ideologías que nacieron con la Ilustración (Castells, 1998a). En la teoría, por otra parte, las críticas a la idea de progreso y a la posibilidad de generalizaciones universalistas pareció patrimonio de los conservadores/reaccionarios hasta el último tercio del siglo XX, que no dudaron en tildar las intervenciones deliberadas y premeditadas para reconstruir el orden social como una nueva fe, la fe de los verdaderos creyentes, negados para entender que el dominio de la acción humana está gobernado por dos grandes principios, perversidad y futilidad, cuya ignorancia, además, genera riesgo (Hirschman, 1991). Desde 1968, sin embargo, el escepticismo sobre el progreso y las virtudes del universalismo ha ganado también adeptos en la izquierda, receptivos a la idea de que el progreso y la reforma hayan conducido a parte alguna, recelosos sobre las buenas intenciones que han empedrado el terreno de este infierno, empeorando el mundo para la mayoría en vez de mejorarlo (Wallerstein 1988, 1997).

Eric Hobsbawm ha sostenido que el mundo actual es, tal vez, el primero en el que, haciendo bueno el despectivo deseo de María Antonieta, la gente común puede alimentarse con brioches en vez de con pan (Hobsbawm, 2000: 144). Ésta es, sin duda, una descripción bastante ajustada de lo que sucede en las sociedades civilizadas, avanzadas, las que viven de hecho en el mismo tiempo o en tiempos similares. No es evidente, sin embargo, que todas las sociedades actuales sean verdaderamente contemporáneas, ni que las sociedades más avanzadas señalen la senda que, a su debido destiempo, todas habrán de recorrer, a pesar de la pesada retórica sobre la globalización. 
Lo más característico de la globalización, escribe Giddens, no es la muy evidente interdependencia económica, ni siquiera los grandes sistemas, como el orden financiero mundial, sino la transformación del tiempo y del espacio en nuestras vidas (Giddens, 1999). De un lado, acontecimientos lejanos, económicos o no, nos afectan más directamente e inmediatamente que nunca. Por el contrario, decisiones individuales, como hábitos dietéticos o decisiones de consumo o de no consumo, tienen consecuencias sobre productores muy alejados de nosotros. Más aún, «la globalización no tiene que ver sólo con lo que hay 'ahí fuera', remoto y alejado del individuo. Es también un fenómeno de 'aquí dentro', que influye en los aspectos íntimos y personales de nuestras vidas» (Giddens, 2000: 24-25).

Así formulado, en efecto, ¿quién lo negaría? Pero, ¿la posibilidad de evitar sus efectos indeseados, de influir incluso en las decisiones individuales, creando si fuera necesario nuevos escenarios de lucha, es de verdad para todos la misma? ¿Estamos todos dotados de similares recursos, de capacidad de negociación, de posibilidades de elección entre la indudable ampliación de opciones vitales que la modernidad ha acarreado?

No es evidente. Las tradiciones, visiones y valores culturales que han sido denominados «modernismo» implican formas de experiencia caracterizadas por la anomia y por una unidad paradójica, una unidad en la desunión (Anderson, 1998: 51-90). Las transformaciones objetivas, acaecidas en los últimos cinco siglos en los pueblos occidentales, habrían permitido, en efecto, distinguir lo nuevo o lo moderno de lo antiguo o lo tradicional, agrupando las distintas sociedades en un continuo progresivo. Pero, a su vez, las transformaciones subjetivas y personales que se producen bajo su impacto habrían provocado necesariamente una tensión dramática en los individuos, en quienes convivirían inseparablemente la sensación de ensanchamiento y de alborozo liberador y una profunda desorientación e inseguridad, desesperación y frustración. Como bellamente escribe Berman, la modernidad es así también un modo de experiencia vital que comparten los hombres y mujeres de todo el mundo, y que se caracteriza por prometer «aventuras, poder, alegría, crecimiento, transformación de nosotros y del mundo y que, al mismo tiempo, amenaza con destruir todo lo que tenemos, todo lo que sabemos, todo lo que somos» (Berman, 1988: 1).

Las oportunidades de destrucción o de alegría no son, de todos modos, equiparables para todos. De un lado, ciertamente, tenemos élites globalizadas, una cosmocracia que ha abolido las restricciones de espacio y que no tiene tiempo, habitantes de un eterno presente, de un tiempo intemporal (Castells, 1997) y, de otro, pobres localizados adheri- 
dos al espacio y superabundantes en tiempo vacío, cuya capacidad de elección se encierra entre el fuego del hambre y la pira de la patera. Más aún, entre ambos extremos parece haberse roto cualquier tipo de vínculo, incluido el de las viejas dependencias de la explotación, de modo que las desigualdades se despliegan ahora en el ningún lugar de la sociedad mundial (Sartori, 1998: 117-121), y la libertad de acción y de elección de los unos se dobla en el implacable destino de los otros.

Debemos especificar, entonces, en qué universalismo creemos o, mejor aún, confrontar la retórica del universalismo abstracto con la férrea realidad de las oportunidades desiguales. No se me ocurre mejor modo que empezar por la infancia, por una infancia anterior a cualquier mérito contraído, pura distribución aleatoria en el espacio físico y social, previa al ejercicio de la responsabilidad individual. Amartya Sen ha señalado que todos los enfoques contemporáneos referentes a la ética de las condiciones sociales son igualitarios respecto a algún valor o actividad central que las distintas teorías consideran especialmente importantes -e importa subrayar, quizás contra la opinión del autor, el término contemporáneo porque en sistemas sociales anteriores bastaba con la igualdad ante Dios como paliativo de la desigualdad mundana-. Dicha igualdad puede, así, referirse a las libertades y a la distribución de bienes elementales (Dworkin), de ingresos y riquezas (los socialismos materialistas), de utilidades (las distintas variantes benthamianas), de libertades (Nozick), de trato legal o político (Buchanan), o de capacidades (Sen), entendidas como la libertad de la que debiera gozar una persona para buscar su bienestar (Sen, 1995).

Otros autores, como Galtung o Tortosa (1992), pueden ser considerados universalistas al vincular el desarrollo con la cobertura de unas «necesidades básicas»-seguridad, libertad, bienestar e identidadque, éstas, sí, resultan ser verdaderamente universales, es decir, aplicables a cualquier política o situación en cualquier tiempo y en cualquier lugar, aunque los «satisfactores» pueden, ciertamente, variar, y aunque deben contemplarse en su totalidad compleja, sin privilegiar a una en detrimento de las otras, eslabonadas en una cadena indisoluble que no sacrifique ninguna en el altar de las demás, como habitualmente ha sucedido.

Ahora bien, en este elemental sentido, ¿cómo ha evolucionado, digamos en los últimos 40 años, la cobertura de dichas necesidades? ¿Qué pasos se han adelantado en favor de una efectiva igualdad de derechos, de títulos de acceso tanto a los bienes y servicios esenciales para un digno mantenimiento de la vida como a la plena ciudadanía? Respondamos, primero, brevemente a estas preguntas, antes de referimos a los impactos de dicha evolución sobre la infancia. 


\section{EL SISTEMA GLOBAL. DESIGUALDAD Y POLARIZACIÓN}

Los Informes sobre el Desarrollo Humano, pese a las no despreciables críticas de que son objeto (Navarro, 1999), permiten medir de modo sintético la magnitud de las desigualdades y su evolución en el tiempo. ¿Qué nos dicen, a grandes rasgos, dichos Informes? Indican, para empezar, que la relación entre el $20 \%$ de la población más rica y el $20 \%$ más pobre, que era de 30 a 1 en 1960 , creció hasta una proporción de 61 a 1 en 1991 y de 82 a 1 en 1995. Mas aún, los mismos Informes hacen notar que las tres personas más ricas del mundo tiene activos que superan el PIB combinado de los 48 países más pobres o menos adelantados y sus 600 millones de habitantes, o que los 225 habitantes más adinerados -los que ocupan los primeros puestos en la clasificación de revistas como Forbes o Fortune- tienen una riqueza combinada igual al ingreso anual del $47 \%$ más pobre de la población, unos 2.500 millones de habitantes (PNUD 1998: 30). El coste de lograr y mantener acceso universal a la enseñanza básica para todos, atención básica de salud para todos, atención a la salud reproductiva de todas las mujeres, alimentación suficiente, y agua limpia y saneamiento para todos, ascendería así a unos 44 mil millones de dólares por año, una cifra equivalente al $4 \%$ de la riqueza combinada de esas mismas 225 personas más ricas del mundo, y casi 20 veces inferior a los gastos anuales en defensa (más de 800.000 dólares anuales).

Sucede, en cambio, que, según el Informe del 99, de los 4.400 millones de personas que viven en los países en desarrollo, tres quintas partes viven en comunidades que carecen de infraestructuras higiénicas básicas, un tercio carece de agua potable para beber, un cuarto no puede acceder a una vivienda adecuada, un quinto está infraalimentado, y otro tercio tiene una esperanza de vida inferior a los 40 años (PNUD 1999: 28). Mientras, los gastos militares en el mundo son más de cien veces superiores al coste de una enseñanza básica para todos; la atención obstétrica y ginecológica para todas las mujeres costaría tanto como se gasta en perfumes en Europa y los Estados Unidos y casi tanto como el consumo de helados en Europa; en fin, el gasto en cigarrillos y alcohol en Europa, o de drogas en el mundo, multiplica casi por dos, por cuatro o por ocho, respectivamente, el coste conjunto de enseñanza básica, agua y saneamiento y salud reproductiva de las mujeres para todo el mundo (PNUD, 1998: 37).

En otros términos, la segunda mitad de este siglo terrible que agoni$\mathrm{za}$-justamente, por cierto, el periodo en el que las políticas de «desarrollo» para los países periféricos adquieren carta de naturaleza oficialha conocido una explosión de desigualdad creciente y vertiginosa, de modo que a las puertas del siglo XXI más de 3.000 millones de personas 
(más de la mitad de la población mundial) viven en la pobreza, con menos de dos dólares al día, y 1.200 millones (una quinta parte de la población mundial, de los que la mitad, 600 millones, son niños ) con menos de un dólar diario (Banco Mundial, 2000).

Pobreza, sin embargo, no es sinónimo de desigualdad, al menos desde una óptica analítica. La desigualdad mide la distancia entre los miembros de una sociedad dada, mientras que la pobreza se refiere a la insatisfacción de las necesidades básicas de una parte de la sociedad de forma involuntaria y permanente, cronificada (Tortosa, 1993: 87 ; 2000). Es decir, teóricamente, es posible el crecimiento de la desigualdad sin un ascenso simultáneo de la pobreza así definida, y no simplemente como una mera diferencia de renta; una «renta baja» respecto a las comunes en una sociedad dada, una «diferencia de ingresos», no equivale a una renta inadecuada para la cobertura de las necesidades básicas (Sen, 1995: 119-133). La pobreza, además, es multidimensional y dinámica. No se refiere sólo a la falta de lo necesario para el bienestar material (ingresos, bienes primarios, recursos) en un momento dado, sino a la denegación de las oportunidades y opciones más básicas del desarrollo humano: una vida larga y decente, dignidad, autoestima, el respeto de los otros y de las cosas que la gente valora en la vida, la participación en la comunidad, poder aparecer en público sin avergonzarse y otros logros sociales más complejos (Towsend, 1993; VV.AA., 1995; PNUD, 1998). Si el ingreso no es la suma total de la vida humana, su carencia no puede ser, por tanto, la suma total de la privación humana, y el acento debe desplazarse hacia el «fracaso de laścapacidades básicas para alcanzar determinados niveles mínimamente aceptables» (Sen, op. cit.: 126), es decir, de las posibilidades reales de convertir los ingresos y los recursos en capacidades para funcionar. En otros términos, los recursos son importantes para la libertad, pero no son lo mismo que la libertad, y los ingresos son cruciales para evitar la pobreza, pero su insuficiencia debe referirse al fracaso para generar capacidades mínimamente aceptables más que a los logros, no independientes de características sociales y/o personales.

En los hechos, sin embargo, la «pobreza capitalista» (Tortosa, 1993) con frecuencia es la expresión de la desigualdad. Es decir, con no excesivas excepciones, los países que suelen contener más pobreza son aquellos que se distinguen por mayores desigualdades de renta, y los países con menor pobreza son aquellos con menor desigualdad, como consecuencia de estados más activos en la redistribución de la renta, en políticas activas de empleo o en la procura de educación, atención sanitaria, vivienda y otras formas de salario indirecto. La existencia de paquetes de bienes básicos y universales, como los nombrados, además, 
normalmente correlaciona positivamente con los contenidos del «buen desarrollo», del desarrollo conforme a las necesidades básicas satisfechas, tanto como su ausencia suele coincidir con los signos del «maldesarrollo» según las necesidades básicas insatisfechas (Tortosa, 2000).

¿Cuáles son, no obstante, los efectos de la extensión de la pobreza y de las disparidades reseñadas sobre la infancia?

\section{LAS PROBABILIDADES DE UN RECIÉN NACIDO}

Se ha calculado que en el año 1999 nació el/la niño/a que elevará a 6.000 millones el total de la población mundial. Carol Bellamy, Directora ejecutiva de UNICEF, ha comentado en un sucinto artículo las probabilidades que enfrenta (UNICEF, 1999a). Para empezar, dicho recién nacido tiene menos de una posibilidad entre 10 de nacer en un hogar relativamente próspero, como el de la mayoría de las familias de los países industrializados o el de la minoría rica de un país en desarroIlo. Tiene, en cambio, 3 posibilidades entre 10 de nacer en situación de pobreza extrema, y 4 entre 10 probabilidades de formar parte de una pobreza sólo ligeramente más llevadera. De hecho, «la mitad de los pobres del mundo son niños, y el número de criaturas que nacen actualmente en condiciones de pobreza es mayor que en cualquier época previa. Se trata de un aumento sin precedentes históricos en la cifra total de personas en la pobreza» (Bellamy, op. cit: 1).

¿En qué repercute sobre la infancia este inquietante aumento de la pobreza? Desde luego, la probabilidad de morir antes de los cinco años es muy superior en países menos desarrollados -que acogen al $85 \%$ de la población mundial-que en los países avanzados. Si sobreviven a esa edad, sin embargo, es improbable que su estado de salud sea aceptablemente bueno. No sólo escasearán los recursos energéticos, sometidos a una intensa sobreexplotación que acentuará su pobreza futura, sino que se verán expuestos a trastornos causados por la contaminación del agua, el saneamiento deficiente y la degradación del medio ambiente, factores que dañarán gravemente su estado ya valetudinario. También es probable, tanto más si viven en áreas rurales o en los enormes cinturones de miseria de las ciudades del Tercer Mundo, que la desnutrición afecte su desarrollo físico y mental, con pesos y tallas inferiores a la media, y dificultades dramáticas para desarrollar su potencial. Casi 12 millones de niños menores de cinco años mueren todos los años innecesariamente, de enfermedades fácilmente prevenibles (vacunas, atención obstétrica), y más de la mitad de los niños de esa edad en Asia Meridional nacen con un peso inferior al normal, mientras 
que casi la mitad de los lactantes africanos no han sido inmunizados contra las enfermedades mortales más comunes (UNICEF, 1999a: 915).

Si viven, además, en el África subsahariana, en la India o Camboya, la posibilidad de quedar tempranamente huérfanos a causa del SIDA se incrementará enormemente, así como la posibilidad de morir ellos mismos a causa de esta pandemia (UNICEF, 1999a: 17-25). En África, por ejemplo, el sida ha matado ya a 11 millones de personas, de las que el 25\% (2,75 millones) eran niños. Un 64\% de los que nazcan en Botsuana en el 2000 morirán de sida antes de cumplir los 5 años, y el número de huérfanos por la misma causa se triplicará por tres en el mismo periodo. $\mathrm{Si}$, de todos modos, sobreviven, su esperanza de vida será sustancialmente inferior a la de los países más avanzados, en una proporción que bien puede ser del doble de años vividos (por ejemplo, entre Japón y Suecia, de un lado, y Malawi y Uganda, en el otro).

La desnutrición, así, incrementa la exposición a las enfermedades, y las enfermedades acentúan la desnutrición, alimentándose recíprocamente en una espiral descendente, configurando una «violación de los derechos humanos tan aborrecible como la tortura, además de constituir una desventaja devastadora para el desarrollo económico de los países» (Bellamy, op. cit.: 3). El desarrollo económico se ve, además, lastrado cuando «cerca de 1.000 millones de personas van a entrar en el siglo XXI sin los conocimientos necesarios para leer un libro o firmar con su nombre, y mucho menos para manejar una computadora o comprender un simple formulario» (UNICEF, 1999b: 7; INTERMON 1999; Mayor Zaragoza, 2000).

En efecto, 855 millones de adultos son analfabetos funcionales -de éstos, 2 de cada 3 mujeres-, y 130 millones de niños crecen sin poder recibir una educación básica, mientras que otros muchos millones de niños languidecen en situaciones donde la enseñanza no alcanza los mínimos requisitos. Las niñas, por otra parte, son las más.afectadas por esta situación, representando 3 de cada 5 niños del mundo en desarrollo que no reciben educación primaria ( 73 de los 130 millones de niños sin escolarizar). Y es que nacer niña, por cierto, sólo incrementará las ya enormes desventajas, tanto peor si, además, se forma parte de un grupo étnico minoritario o de poblaciones indígenas mayoritarias, pero radicalmente excluidas. Las niñas reciben así un trato más negligente y peor alimentación; se verán discriminadas en mayor proporción del acceso al estudio, o interrumpirán antes su escolarización por ahorro de costes o para ocuparse de tareas domésticas en el hogar; sufrirán diversos grados de violencia y abuso, incluyendo la mutilación genital (que es infligida a dos millones de niñas por año), o la prostitución infan- 
til forzosa, que afecta a muchos millones en todo el mundo (Congreso Mundial 1996; UNICEF, 2000); resultarán embarazadas en la adolescencia (como la mitad de las mujeres en África o la tercera parte en América Latina), y se convertirán en madres antes de madurar como mujeres. Si no perecen en el alumbramiento -tienen el doble de posibilidades de perecer en el parto que una mujer adulta-, los hijos de esas niñas pesarán normalmente menos de $2,5 \mathrm{~kg}$., por deficiencias nutricionales de la madre, y su insuficiente desarrollo físico prefigurará una mayor exposición a la enfermedad, dificultades intelectuales y un desempeño escolar deficiente, que lastrará sus oportunidades vitales.

Sin embargo, los beneficios de la educación, al menos de la básica, para el progreso de las naciones, y singularmente de la educación de las niñas, no necesita ser resaltada (Núñez y Tortella, 1993). La educación de las madres reduce la mortalidad de lactantes y niños, y la de las mismas madres en el parto. Los hijos de madres más educadas tienden a estar mejor nutridos, a padecer menos enfermedades, y tienen más probabilidades de recibir educación y alfabetización. Cuantos más años de educación haya recibido una mujer, tanto más tardío será su matrimonio y menor el número de hijos que probablemente tendrá. La educación de las mujeres tiene, en fin, profundos efectos no sólo personales (sobre los propios hijos, o sobre ellas mismas, al incrementar sus oportunidades y opciones, y permitir la evitación de situaciones de opresión y abuso), sino sociales, al incrementar su receptividad e influencia en iniciativas de desarrollo en las que desempeñan un papel tan central como frecuentemente ignorado (Declaración de Beijing y Plataforma para la acción, 1996: 73-89 y 245-261; UNICEF, 1999b: 51-62).

Los niños, además, trabajan y mueren como soldados o víctimas en guerras en las que resultan ser, con mujeres y ancianos, los más perjudicados (OIT, 1996; UNICEF, 1999b; Sedky-Lavandero, 1999). Según la Organización Internacional del Trabajo, en efecto, 250 millones de niños entre los 5 y los 14 años trabajaban en 1996 por un salario en los países en desarrollo, de los cuales 120 millones lo hacían a tiempo completo. Dicho cálculo descuenta, no obstante, un incremento del trabajo infantil que la OIT juzga significativo pero que no cuantifica, en Europa Oriental y en las economías asiáticas en transición hacia el mercado. Existe, además, abundante evidencia empírica sobre un crecimiento explosivo del trabajo infantil en los mismos países desarrollados, relacionado con el deterioro de las condiciones de vida y de trabajo de los trabajadores más descualificados, con el incremento de la inmigración ilegal, y con el auge de la pequeña economía criminal. La esclavitud misma, el trabajo cautivo, no ha muerto, y afecta sobre todo a niños que son ofrecidos como garantía por deudas contraídas por los padres, sobre todo en Asia (India, Thailandia, Filipinas). 
En cuanto al impacto de la guerra sobre los niños, en 1996, y sólo durante la última década considerada, UNICEF calculaba que, en los conflictos no estructurados posteriores a la Guerra Fría -conflictos que tienen que ver con guerras civiles internas y la desintegración de numerosos Estados- resultaron muertos dos millones de niños, entre cuatro y cinco millones quedaron inválidos, más de un millón quedaron huérfanos o separados de sus padres, 12 millones perdieron su hogar y más de 10 millones sufrieron traumas sicológicos difícilmente reversibles. En el mundo de la posguerra fría, según OXFAM, el $90 \%$ de las víctimas de la guerra son civiles, el 75\% de los refugiados y desplazados son mujeres y niños, y de las víctimas de la guerra el 50\% son niños (OXFAM, 1998: 8), mientras que en la Primera Guerra Mundial sólo el 5\% de las víctimas fueron civiles, cifra que se elevó ya al $48 \%$ en la Segunda Gran Guerra. Trescientos cincuenta mil niños son, por otra parte, usados en conflictos armados de diverso tipo como soldados baratos, obedientes, fácilmente adoctrinables, fanatizados hasta su propia muerte, mientras que un tropel de niñas prestan servicios domésticos, sexuales o incluso militares, sometidos/as a una brutalidad incesante (Sedky-Lavandero, 1999).

Hasta aquí, sin embargo, me he referido sólo a lo más probable. En la otra cara de la luna, sin embargo, donde las oportunidades materiales abundan, y el horizonte de capacidades se amplía inimaginablemente, los menores parecen sujetos a nuevas de formas de vulnerabilidad, impensables en el que iba a ser el «siglo de los niños», según la célebre fórmula de la educadora feminista sueca Ellen Key. Esa acrecentada vulnerabilidad, aun sin parangón con las situaciones predominantes en los países periféricos, presentan, sin embargo, cierta similitudes con procesos que se desarrollan en el conjunto del planeta. Déjenme explorarlas brevemente, antes de intentar poner de relieve los procesos subyacentes a esta fatal evolución.

\section{MENORES EN EL PARAÍSO. UNA EVOLUCIÓN INESPE- RADA.}

Como ha señalado Therborn, «las dos fuentes fundamentales determinantes en el establecimiento del concepto de minoría de edad han sido las legislaciones relativas a la educación obligatoria y las que regulan las condiciones de trabajo» (Therborn, 1993: 87). La concepción moderna del menor está, además, íntimamente relacionada con el desarrollo del Estado moderno y del mercado, con la lenta emergencia de un individualismo igualitario, que se tradujo, en el ámbito de las relaciones familiares, en el concepto de «familia centrada en el menor», y en 
la lenta consecución, primero por parte de las mujeres, desde la segunda mitad del XIX, de la igualdad de derechos frente a la desigualdad de obligaciones que soportaban como esposas, hijas y por su condición de mujeres en sí. El proceso de emancipación de los menores del poder absoluto de los padres fue, sin embargo, más lento y tardío, inspirado curiosamente en la protección contra el trato cruel que se dispensaba a los animales, y se construyó en alianza conflictiva con la liberación progresiva de la mujer del poder patriarcal. Es decir, los dos procesos (emancipación de las mujeres y reconocimiento de los derechos de los niños), como señala Therborn, «han estado estrechamente ligados pero no son ciertamente idénticos y han competido e incluso entrado en conflicto entre sí» (Therborn, ibíd: 96). Ambos, sin embargo, han resultado decisivos en el resquebrajamiento de esa estructura, tan antigua como la historia, y probablemente tan antigua como la sociedad misma, que es el patriarcado.

¿Qué es el patriarcado? El patriarcado es una estructura básica de las sociedades contemporáneas, y probablemente de todas las sociedades conocidas. El patriarcado, en efecto, se caracteriza por el predominio, arraigado en las instituciones, de los hombres sobre las mujeres y los hijos en la estructura familiar. Por supuesto, el patriarcado permea y modela la organización de la sociedad en su conjunto (economía, política y cultura), incluyendo las relaciones interpersonales, pero su piedra miliar son las pautas de relación que se establecen en el interior de los grupos domésticos y que han mostrado una increíble resistencia al cambio a lo largo de la historia.

Hace 151 años, en el Manifiesto, sin embargo, Marx y Engels ya observaron que, bajo las reglas del capitalismo, los miembros de las sociedades avanzadas se veían sometidos a una incesante conmoción, a una inquietud perpetua, a un constante movimiento. Así, según la fórmula ya clásica: «Todo lo sólido se desvanece en el aire; todo lo sagrado es profanado, y los hombres, al fin, se ven forzados a considerar serenamente sus condiciones de existencia y sus relaciones recíprocas».

Pues bien, no con serenidad sino con mucho dolor, de forma traumática, eso es precisamente lo que ha sucedido. El velo de emocionante sentimentalismo que encubría las relaciones familiares se ha rasgado, pero en su lugar no se han desarrollado nuevos acuerdos, nuevos lazos, nuevas relaciones más recíprocas y democráticas, con menos envoltorio místico si se quiere, pero también menos sujetas al frío cálculo, al cruel pago al contado, para seguir utilizando la terminología de Marx.

Los datos de la crisis de la familia patriarcal son bien conocidos, 
aunque, tal vez, escribiendo en España -uno de los pocos países (relativamente) avanzados, junto con Japón, en el que el familiarismo permanece de momento sólido- no esté de más recordar algunos indicadores elementales (Burguière, 1988). Primero, en vez del compromiso a largo plazo, estamos asistiendo, desde los años 60/70 hasta la actualidad, a un constante incremento de la tasa de divorcios que, salvo en la Europa meridional, oscila entre un tercio y más de la mitad de los matrimonios celebrados. Segundo, se retrasa la edad del matrimonio, y crecen sustancialmente la cohabitación antes del matrimonio, las uniones libres, el porcentaje de hogares con un solo miembro, y la proporción de hogares con un solo progenitor (normalmente mujer) con hijos dependientes. Tercero, en consecuencia, la proporción de niños nacidos fuera del matrimonio se incrementa sustancialmente. En general, concluye Castells tras revisar los indicadores estadísticos disponibles tanto de países desarrollados como no desarrollados, «la familia patriarcal está en proceso de convertirse en una forma minoritaria del modo de vida de la gente. En los Estados Unidos, sólo en torno a un cuarto de los hogares totales en los años 90 cumple con el tipo ideal de una pareja con hijos. Si añadimos la calificación 'con los hijos biológicos de la pareja' la proporción desciende notablemente» (Castells, 1998a: 180). En el mismo país, por otra parte, la proporción de hogares tradicionales, con «varón proveedor» y esposa ama de casa a tiempo completo, no supera el $7 \%$ del total de los hogares.

Importa, además, resaltar que estas tendencias no son privativas de los países industrializados, sino que afectan también a buena parte de los países periféricos - la triste excepción a esta triste regla son los países en los que política y culturalmente predomina alguna forma de integrismo religioso-, de un modo que sugiere que las mismas presiones tecnológicas, económicas, sociales y culturales subyacen en lugares muy diversos a la crisis de la familia patriarcal, aunque modificadas por historias y culturas idiosincrásicas (Giddens, 2000: 65-79).

Ahora bien, ¿de qué forma afectan estas tendencias a la vida de los niños? En Estados Unidos, por ejemplo, la proporción de hijos que en 1991 vivían con sus dos padres biológicos era sólo del 50,8\%. De hecho, uno de cada cuatro hogares norteamericanos cuenta con un solo progenitor, pero de ellos un $90 \%$ está regido en exclusiva por la madre, un proceso tan intenso en las últimas décadas que se ha podido hablar de una «fatherless America» (una América sin padres), en referencia al libro de David Blankenhorn que desencadenó una intensa polémica a mediados de los 90 .

Un rasgo sistémico, en efecto, de las crecientes crisis matrimoniales -o de las separaciones, más numerosas aún, en las uniones de hecho- 
es la dificultad cada vez mayor para compatibilizar matrimonio, trabajo y vida, dificultad que se convierte en carga insoportable en el caso de la mujeres, ante la renuencia del varón a asumir su parte alícuota de responsabilidad en el trabajo doméstico y en la crianza de los hijos. En el caso de los Estados Unidos, por ejemplo, la fuerte orientación al mercado laboral tanto de hombres como de mujeres determina que «la media de conversación entre padres e hijos sea de 7 minutos en los días laborables y 20 en cada uno de los días del fin de semana» (Verdú, 1996: 119).

Por otra parte, el porcentaje de niñas que quedan embarazadas en EE.UU. en torno a los 15 años es actualmente tan alta o más que en los países del Tercer Mundo (por la incidencia de los embarazos adolescentes en los guetos), y la reiteración de admoniciones represivas ha embotado su receptividad y permitido el rebrote del consumo de drogas (blandas y duras, legales e ilegales), de los cíclicos episodios de violencia colectiva sobre el fondo de una inseguridad estructural -más de 150.000 niños acuden diariamente a clase con armas de fuego en EE.UU.-, y un auge sin precedentes de la depresión, la ansiedad y el aislamiento entre los niños (Ibíd: 117-127).

Es decir, para resumir, junto a la disposición de una riqueza de recursos inimaginable, los niños de las clases medias en los países avanzados no es improbable que vivan en condiciones de «aislamiento social e inseguridad emocional como consecuencia de las tasas de divorcio, el exceso de trabajo que atenta contra la vida familiar y la disminución del contacto humano, y que los jóvenes sufran un creciente estado de alienación, que sean considerados más como consumidores que como niños» (Bellamy, op. cit.: 1). En cuanto a los hijos de los pobres y del creciente ejército de los excluidos -el «Tercer Mundo en casa» de los países avanzados-, su situación, desde el punto de vista de su capacidad para llevar una vida digna, para alcanzar los funcionamientos sociales normales, no es tan diferente, pese a los mayores recursos materiales, de la de los pobres del Tercer Mundo. En las sociedades avanzadas, una privación relativa en el ámbito de los ingresos o en la cesta de bienes disponible-por ejemplo, no tener televisión, coche o teléfono, objetos de lujo en sociedades menos desarrolladas- puede producir, en la terminología de Sen, una privación total en el ámbito de las capacidades. El dolor y la destrucción, el deshonor social, el analfabetismo funcional y su más severa consecuencia -la dificultad casi insalvable en la obtención de un trabajo medianamente digno-, el hostigamiento y el encarcelamiento, son su más probable horizonte, como atestigua la experiencia de los guetos en EE. UU. o en las ciudades de la Europa avanzada, una especie de sorda guerra civil interna que resucita el espectro de las clases peligrosas, de las dos ciudades de Dickens y 
Disraeli, la una amurallada, la otra errabunda y anómica.

Con un número creciente, además, de niños en la pobreza -el 22\% de los niños estadounidenses viven en la pobreza, y uno de cada tres niños es pobre en el Reino Unido, según un reciente estudio de la London School of Economics, dirigido por Paul Gregg (Gómez, 1999)- el desmoronamiento de las familias rompe la última, aunque contradictoria, estructura protectora de la infancia, en un momento en el que el Estado se desresponsabiliza de la procura de abrigo y el reformismo social y sus agentes sufren una profunda crisis o se baten en retirada. La crisis del patriarcado, en efecto, escribe Castells, «destruye la familia nuclear tradicional sin reemplazarla, haciendo que las mujeres y los niños paguen por ello (...) De acuerdo con los análisis documentados de Rodgers y Lerman, existe una estrecha relación entre el cambio de la estructura familiar y el aumento de mujeres y niños pobres en EE.UU. Quien desafía al patriarcado lo hace a su propio riesgo y al de sus hijos» (Castells, 1998b: 186).

Más aún, la crisis de la familia, en su doble papel de normalizadora y objeto de transgresión, alienta la institucionalización del deseo, su expansión perversa y descodificada. El sorprendente auge de la pedofilia, la pornografía o la prostitución infantiles se nutre así, probablemente, desde el lado de la oferta, de la extensión de la pobreza y la crisis de la familia y, desde la demanda, de la posibilidad de expresión de una violencia sin fin y sin objeto, de una transgresión pura y enfermiza facilitada por la mercantilización de todas las cosas («todo lo sagrado es profanado»: es decir, todo vale si es rentable, cualquier forma de conducta se hace moralmente permisible en el momento en que se hace económicamente posible y adquiere «valor»), y por la existencia de redes criminales globales y el anonimato permitido por la conexión electrónica o el turismo masivo (Castells, 1998a: 268; 1998b: 181-184).

Estamos, pues, bien lejos de esa «democracia de las emociones en la vida diaria» que propugna Giddens (Giddens, 2000: 76), aunque sin duda éste es un objetivo deseable. Primero, porque la igualdad sexual es sólo un benigno desiderátum y porque «la mitad del cielo» se ve, casi en su mayoría, privada de los derechos de ciudadanía y sometida a las más diversas formas de vejación y violencia de género, que se añaden a las violencias que recaen sobre casi todos. De hecho, según UNICEF, casi la mitad de las mujeres del mundo tiene a su enemigo en casa, ya que entre el 20 y el $50 \%$ de las mujeres y niñas son objeto de violencia física por parte de un miembro varón de su propia familia. Además, entre el 40 y el $60 \%$ de los abusos sexuales dentro del seno familiar son cometidos contra niñas menores de 15 años, que padecen una violencia doméstica perpetrada por varones que están o que han estado en posi- 
ción de confianza, intimidad o poder. Segundo, porque la violencia contra las mujeres afecta, a través de múltiples vías, a sus hijos y a sus posibilidades de supervivencia-los hijos de mujeres víctimas de la violencia doméstica tienen seis veces más posibilidades de morir antes de los cinco años- (UNICEF, 2000).

La violencia de género, el ciclo de abusos que se manifiesta en diferentes formas y etapas de la vida de las mujeres se dobla así en deliberada crueldad contra la infancia, una crueldad que incluye en su catálogo de horrores la desnutrición, el incesto, la mutilación genital -dos millones anuales que se suman a los 130 millones de mujeres ya mutiladas-, la prostitución obligada, el matrimonio forzado, las represalias por impago de la «dote» o por «disputas domésticas»-que incluyen las quemas con fuego o con ácido en la India o Pakistán-, la violación y el «asesinato por honor».

\section{UNA CREACIÓN DIFÍCIL DE AMAR. LA DESTRUCCIÓN DE LA INFANCIA}

Creo que fue Camus quien escribió que le costaba amar una creación en las que los niños eran torturados. Los tiempos de Camus no fueron, como casi ningún tiempo, buenos para los niños -Truffaut, por ejemplo, estrenó Los cuatrocientos golpes el mismo año en que Camus moría, y desde entonces muchos cineastas han filmado la lenta agonía de los niños en los países ricos y en los periféricos-. En el momento de su muerte, 1960, Camus trabajaba en una novela inacabada, El primer hombre, que sin embargo es uno de los textos más intensos y bellos de la segunda mitad de este siglo terrible, y una reivindicación, a un tiempo, de la infancia como la verdadera patria de los seres humanos (SaintExupéry), y de la dignidad de una pobreza escarnecida. Me gustan esos textos en los que la pobreza nos es presentada no sólo como un estado sumamente doloroso y frágil, sino como una escuela corajuda, como la fragua de un orgullo inextinguible, como la trabajosa construcción de un decoro asediado, que requiere de la movilización de muchos recursos, incluyendo la alegría, el extraño furor de vivir aun en la penuria. Fue también Camus, al fin y al cabo, quien escribió en El Verano: «Sí, existe la belleza y existen los humillados. Sean cuales sean las dificultades de la empresa, querría no ser jamás infiel ni a la una ni a los otros».

No lo fue. $\mathrm{Al}$ menos, además, los años 60 representaron el segundo gran periodo de esfuerzo legal en este siglo -el primero comienza a mediados del primer decenio y termina en los años 30- por apuntalar los derechos de los niños, esfuerzo que culminará con la celebración de la Convención de las Naciones Unidas sobre Derechos de los Niños de 


\section{9 y de la Conferencia Mundial sobre Menores de 1990.}

Los nombres de importantes acuerdos y las fechas, sin embargo, no deben inducirnos a engaño. En realidad, como he señalado anteriormente, citando a Carol Bellamy, las dos últimas décadas se caracterizan por un dramático retroceso de las conquistas sociales y de los derechos de los niños obtenidos con mucho sufrimiento en décadas anteriores. Porqué y cómo se ha producido la demolición de esa ciudadela de derechos, trabajosamente erigida, es un asunto que rebasa la pretensión de este artículo, y que además debiera ser objeto de una reflexión colectiva. José María Tortosa ha escrito recientemente que la situación del mundo en este fin de siglo/fin de milenio replantea, a escala global, los dilemas que las sociedades avanzadas enfrentaron en las postrimerías del pasado siglo (Tortosa, 2000). Estoy de acuerdo con él, y con todos los que claman en el próximo siglo por un mundo mejor frente a un «mundo feliz», por la necesidad de nuevos y explícitos contratos frente a la ya no tan utópica proyección huxleyana (Mayor Zaragoza y Bindé, 1999). Déjenme, sin embargo, para finalizar nombrar siquiera los que, para mí, son los obstáculos, no sé si remontables.

Primero, tenemos la poderosa industria de la muerte, de la matanza más o menos organizada, que, como hemos visto, consume recursos anuales ( 866.000 millones de dólares) que multiplican por más de 20 veces los recursos necesarios para que la vida pudiera empezar a considerarse una vida digna para todos, los requisitos mínimos de una existencia humana -educación básica, alimentación mínima adecuada, agua potable, infraestucturas sanitarias elementales, atención a la salud reproductiva de las mujeres-, cuyo coste se evalúa en unos 44.000 millones de dólares anuales. El sistema de la guerra, además, recluta niños para la muerte, bien como soldados, bien como víctimas, en una proporción inédita en periodos históricos anteriores, ofreciendo banderas o un espurio sentido de pertenencia a cambio de la propia vida.

Segundo, tras ese inmenso despilfarro está un sistema que ha creado no sólo una desigualdad creciente y escandalosa en la distribución de la renta o en el consumo de recursos (el $82 \%$ de las rentas mundiales y el $86 \%$ de los recursos renovables y no renovables son consumidos por el $20 \%$ opulento de la humanidad, que acapara además el $93 \%$ de los accesos a Internet), sino que ha generado pobreza y exclusión en todo el mundo y que amenaza la sostenibilidad de la vida humana sobre el planeta Tierra (PNUD, 1999). Es, además, ya un secreto a voces que la promesa de un desarrollo para todos, a semejanza del de los países avanzados, se enfrenta a límites no económicos, sino biológicos, físicos y químicos, que determinan que harían falta tres planetas como el nuestro para que todos pudieran mantener el consumo que hoy pre- 
valece en Norteamérica. Cualquier promesa de «desarrollo» que no parta de esta sencilla premisa, que no contemple una disminución significativa y/o una muy superior eficiencia en el consumo de recursos por parte del Norte desarrollado, no sólo es ilusoria, un señuelo o una racionalización interesada, sino también una invitación a compartir la responsabilidad de un desastre seguro.

Por añadidura, los rasgos básicos del sistema, sus fines y motivaciones esenciales, se han visto extraordinariamente reforzados en las últimas décadas por la desregulación radical de las economías, y el debilitamiento, drástico en los países menos desarrollados, de la acción correctora y protectora del Estado, a hombros de una globalización - «sociedad mundial sin gobierno mundial», en expresión de Ulrich Beck (Beck, 1998b) - facilitada por un uso enemigo para la mayoría de las potencialidades, en sí mismas positivas, contenidas en las nuevas técnicas.

La expresión, por otra parte, más dramática en las últimas décadas de las nuevas reglas de la economía mundial ha sido la «crisis de la deuda», que lastra aún dramáticamente las oportunidades de desarrollo de muchos países terceros y de cientos de millones de personas. No es éste el momento adecuado para recordar las razones de esta crisis, una instructiva historia que involucra como agentes del drama a un sistema financiero internacional irresponsable pero garantizado, a unas élites periféricas depredadoras de sus propias sociedades, y a instituciones de gobierno de la economía mundial (FMI, Banco Mundial, G7, OMC) que, éstas sí, han resultado ser activos propagadores del «riesgo moral» y activistas de la explosión del desorden a escala mundial (Estefanía, 2000; Strange, 2000).

Sin embargo, «la deuda tiene cara de niño» (Rampahal, en UNICEF, 1999a: 27-33). La mayor parte del peso de la deuda «recae sobre las mentes y los cuerpos de los niños» (ibíd), hipotecando sus vidas y trabajos a bancos y gobiernos de los países ricos por préstamos que financiaron proyectos que nunca les beneficiaron. Los países del África subsahariana, por ejemplo, gastan más en el servicio de su deuda que en la salud y educación de sus 306 millones niños. En los países en desarrollo, el promedio per cápita de la deuda es de 417 dólares -tal vez importe subrayar, a efectos comparativos, que en 1993 el PIB per cápita de los 48 países menos adelantados era inferior a 750 dólares anuales frente a los 23.000 de los países de ingreso alto, según el Banco Mundial-, pero en países como Nicaragua cada lactante viene al mundo con una deuda de 1.213 dólares, y en el Congo de 1.872 dólares. Los países al sur del Sahara gastan en el servicio de la deuda entre una cuarta y una tercera parte de sus presupuestos nacionales, y un $40 \%$ en los 
países más endeudados, lo que se traduce en desatención a políticas de sanidad y educación básicas, en la muerte de millones de niños y en la atrofia irreversible de las mentes y los cuerpos de otros más numerosos.

A cambio de la inmensa transferencia de recursos desde el Sur hacia el Norte que constituye el pago de la deuda -sólo entre 1983 y 1990 los países deudores pagaron un billón de dólares-, el monto de la deuda, que era de 800.000 millones de dólares en 1983, no ha cesado de incrementarse, a causa del pago de los atrasos y de nuevos créditos para cubrir lo impagado, ascendiendo a cerca de dos billones de dólares en 1997. En injusta reciprocidad, por el contrario, la ayuda oficial al desarrollo que, según las recomendaciones de Naciones Unidas, debía tender hacia la exigua meta del $0,7 \%$ del PNB de los países industrializados, ha descendido desde el 0,33 de 1992 hasta el 0,21 actual, regresando una cuarta parte de la ayuda bilateral que reciben los países pobres en concepto de pago de la deuda (Ramphal, op. cit.: 28).

Tercero, los procesos económicos descritos $-\mathrm{y}$ sus correlatos, la extensión de la pobreza y de la exclusión social, así en los centros como en las periferias-alientan la implosión de sociedades y economías enteras, la desintegración de las sociedades tradicionales, el debilitamiento radical de las instituciones protectoras estatales o de la sociedad civil (sindicatos, asociaciones cívicas, cooperativas, Iglesias), y el derrumbe de las familias como último dique de defensa de los niños.

Nada de esto es nuevo. En los países avanzados asistimos a parecidas «catástrofes culturales», asociadas a la «gran transformación» del siglo XIX, a la expansión de un mercado autorregulado, el sueño utópico y periódicamente renovado de las retóricas y de las políticas de la intransigencia reaccionaria (Polanyi, 1989; Hirchman, 1991). Hoy como ayer, por tanto, afrontamos el mismo desafío, pero a una escala inédita, a escala global. Es decir, con las dificultades adicionales de que no hay un Tercer Mundo para el Tercer Mundo que financie su bienestar relativo, como sucedió en Europa desde la segunda mitad del XIX con la tercera gran expansión colonial, y de los límites que el medio ambiente impone a la expansión indefinida de la producción y del consumo y sus secuelas (el agotamiento, la contaminación, los residuos, el cambio climático, etc.). Nos encontramos, pues, en una encrucijada, en una bifurcación probable, para utilizar la terminología de Prigogine, de un sistema sumamente inestable y que fluctúa lejos del equilibrio (Prigogine, 1997a y b). Para contener los signos, cada vez más evidentes, de un caos que ya está entre nosotros, es necesario, desde luego, organizar la resistencia, nada fácil, de los más damnificados, y probablemente, como antaño, contar con el consenso mínimo de las élites ilustradas sobre el 
hecho de que sus actividades y, sobre todo, las reglas y valores que las vehiculan son dañinas para ellos mismos, que amenazan la continuidad de la vida, la de los niños que son su futuro y la de su soporte físico, químico y biológico.

Cuarto, para que se inviertan las tendencias descritas, la pulsión de muerte destructiva que parece dominar al sistema, sin corrección alguna en las últimas décadas, se imponen no sólo frenos explícitos y eficaces (por ejemplo, el control de los movimientos de capitales a corto plazo, capaces de devastar economías enteras, haciéndolas retroceder en pocos días lo costosamente avanzado en muchos años; o la reconstrucción de los Estados, los únicos centros de poder efectivamente democratizables, más activos en la procura de bienestar para sus ciudadanos; o la recomposición de la capacidad de mediación de la política, deslegitimada por una extensa corrupción y por su sujección a las leyes de una economía al margen de todo control social, moral o político; o la reactivación de una sociedad civil que, contra lo que afirma la ortodoxia liberal, resulta ser menos densa y rica cuando el Estado y la política, la esfera pública, se deslegitima y debilita, como muestra la experiencia del Bloque del Este ), sino un cambio cultural.

El requisito mínimo de ese cambio, su elemental precondición, es desde luego la expansión de la educación para todos y a lo largo de la vida, el desarrollo de una educación planificada como derecho (UNICEF, 1999b), y en tanto que proyecto de ciudadanía e instrumento de democratización. Sin dicho proyecto, sin duda, las bases culturales del actual apartheid social resultarán reforzadas por un apartheid escolar que distribuye a los elegidos y a los condenados según una lógica más social y política que meritocrática (Mayor Zaragoza, 2000).

El cambio cultural, sin embargo, no puede referirse sólo al universo educativo. Las mujeres y las niñas se ven sometidas a diversas formas de discriminación -más o menos sutiles, más o menos brutales-, con consecuencias terribles para ellas mismas, los niños y las mismas estructuras familiares. No habrá, por tanto, recomposición social duradera sin un reparto más justo de todas las formas de trabajo, incluyendo el trabajo doméstico y la atención a los hijos, y sin políticas activas que favorezcan su plena incorporación en condiciones de igualdad a la vida económica, social y política, y a los proyectos de desarrollo. Singularmente, una familia democratizada, apoyada por políticas sociales amplias que proporcionen apoyo material y sicológico, y que vele por la autonomía y la integridad de los menores, parece ser la única alternativa viable a la disolución de las estructuras familiares en el descompromiso personal o en contratos y acuerdos puntuales (Castells, 1998a: 259262). Sin embargo, la resistencia que los varones oponemos a la 
renegociación de los roles sexuales constituye un severo límite a esa recomposición de la familia, cuyo coste es la carga brutal que soportan las mujeres -muchas en condiciones personales y económicas terribles, en lucha desigual por la supervivencia y por su propia autonomía-, y el desamparo de los niños, el incremento brutal de los abandonos, el trato negligente o los malos tratos, con consecuencias duraderas en su psique y en la configuración de sus identidades futuras, supuesto el círculo maligno por el que las víctimas de hoy tienden a convertirse en los verdugos de mañana.

La crisis de la familia, sin embargo, no es exclusivamente un asunto de hombres y mujeres. Un rasgo central de la presente crisis es, en efecto, que el debilitamiento de los vínculos familiares se verifica en el contexto del retroceso de la acción correctora del Estado y de condiciones de vida y de trabajo que dificultan gravemente el desempeño congruente y simultáneo de los distintos roles sociales (Navarro, 1997). La intensificación del esfuerzo laboral de ambos progenitores en condiciones de una creciente individualización y vulnerabilidad de la relación laboral, el descenso de las rentas de buena parte de la fuerza de trabajo, la crisis de otras instituciones clásicas de integración social -la escuela fundamentalmente, los grupos de iguales-, y la elevación de las barreras de entrada en el mercado de trabajo, someten a una tensión dramática la vida familiar, sobrecargándola de demandas difícilmente compatibles. El individualismo como tendencia cultural disuade, además, la subordinación de los propios deseos y necesidades a los de la familia cuando, en los hechos, las necesidades de ésta son definidas no a través de la negociación de los distintos roles sino según las reglas de un poder patriarcal, con exención de obligaciones por parte del varón.

Un nuevo contrato cultural implica, pues, preservar las potencialidades positivas del individualismo - la libertad de acción y de juicio, la potenciación de las propias capacidades, el «empowerment», la consideración de los deseos y necesidades individuales-, precaviéndose de sus efectos disolventes -la lucha de todos contra todos, el cainismo darwinista, la disolución de la cooperación en la racionalidad de la conducta egoísta, la subordinación al propio interés de los intereses colectivos, la lógica del «gorrón» y del «individualismo posesivo», los pequeños egoísmos privados, la cultura narcisista-.

\section{CONCLUSIÓN}

Isaiah Berlin sostuvo, frente a los que él llamaba ingenieros sociales o del alma, que los sistemas de valores carecen de coherencia interna, y que el conflicto de valores -libertad frente a igualdad; equidad frente 
a eficiencia; justicia frente a clemencia; tolerancia frente a orden; justicia social versus libertad individual; seguridad frente a libertad-es intrínseco a la vida humana y, aunque mitigable, trágicamente ineliminable en los hechos, en las cosas, si bien no en los conceptos, las palabras, que todo lo soportan. También mantuvo que, como escribió Kant, «con madera tan torcida como de la que está hecho el hombre no se puede construir nada completamente recto», y que, puesto que la razón humana es irremediablemente imperfecta y los valores incompatibles, las elecciones vitales, personales o sociales, aun las tomadas a la luz de la razón, son un acto de voluntad, de instinto, de emoción, una jugada decidida en la oscuridad, según su propia y bella fórmula (Berlin, 1992), si bien Perry Anderson ha discutido convincentemente la apropiación que Berlin hace de las Ideas de Kant (Anderson, 1998: 330-332).

Es posible, por supuesto, sostener lo contrario: aspirar a la utopía de una armonía sin mácula o, más razonablemente, a la utopística, a un mundo en el que la igualdad política, el crecimiento económico, la organización eficiente y la justicia social sean compatibles entre sí y con la libertad individual y universal, donde el universalismo deje de estar en conflicto con el particularismo, o la solidaridad con el individualismo, o las lealtades públicas con las privadas (Wallerstein, 1999); pretender, en fin, un mundo que aboliera estos «falsos dilemas» y en el que la verdad, la virtud, la belleza y la felicidad coincidieran y no existieran más conflictos entre valores, más dilemas morales, más incompatibilidad entre lo correcto y lo correcto, ni más tragedia.

Sabemos, de hecho, que esa fue la aspiración, el impulso originario de la Ilustración que animó La paz perpetua (Kant), o el Esbozo de un cuadro histórico de los progresos del espíritu humano (Condorcet). Pero sabemos también que ese sueño se ha convertido frecuentemente en pesadilla, que alentó el racismo imperialista, y que «esa universalización abstracta practicada por el imperialismo ha sido una forma de asesinato disfrazado» (Laroui, citado en Wallerstein, 1997: 23). Tal vez, por tanto, la esperanza de un futuro mejor, el sapere aude, tiene también un poder mortal, tal vez más mortal aún que las tradiciones, los atavismos y las creencias ultramundanas contra las que originariamente se insurgió, como ilustra la experiencia de este siglo terrible o de nuestro actual mundo desbocado. $\mathrm{O}$ tal vez cualquier idea, incluida la más noble, es deformable hasta el fanatismo por el error irreformable que somos.

No hay así ningún motivo para el optimismo, ninguna esperanza de reconciliación, pero tampoco ninguno para la inacción o el quietismo. La civilización capitalista es tan bárbara, tan poco civilizada, si no menos, que las anteriores, como atestiguan los terribles datos sobre el 
estado de la infancia que apenas hemos enunciado. Incluso los beneficios de la educación, en los que he hecho tanto hincapié a lo largo de este texto, son profundamente discutibles y, desde Iuego, no ha hecho disminuir sino tal vez incrementar algunos de los peores rasgos del sistema, a través de una superior capacidad de «racionalización»-en el doble sentido weberiano y freudiano- de la infamia. Así que tenemos trabajo, y el trabajo que tenemos supera en mucho nuestras fuerzas, tal vez nuestra misma voluntad poco heroica. Podemos empezar en casa, con nosotros mismos o con la familia - «el entendimiento humano se ve forzado a elegir entre la perfección de la vida o la perfección del trabajo», escribió Yeats-, o en el ámbito laboral, en el barrio o en la ciudad, en lo que se denomina lo «local» o en la esfera del Estado, o intentar modificar el universo - «¿me atreveré? ¿Me atreveré a perturbar al universo», se preguntaba Prufrock, el enamorado eliotiano-.

No importa, pero debiéramos saber, pese a que tan a menudo lo ignoramos, que si trabajamos con los niños, por los niños, estamos trabajando por la vida, por el futuro de la vida, del mismo modo que, como escribió Francisco Umbral, «por el mal de los niños descubrimos que la vida no es noble ni buena ni sagrada. Descubrimos lo que la vida tiene de alimaña ciega, de cebarse en sí misma». Bien, no sé si la vida, pero sí esta vida, la que tenemos, la que debiéramos modificar, si puede ser, un poco concertados.

\section{BIBLIOGRAFÍA}

ANDERSON, P. (1998): Campos de batalla, Barcelona, Anagrama.

BANCO MUNDIAL (2000): En el umbral del siglo XXI. Informe sobre el desarrollo mundial 1999-2000.

BECK, U. (1998a), La sociedad del riesgo: hacia una nueva modernidad, Barcelona, Paidós.

BECK, U. (1998b): ¿Qué es la globalización?, Barcelona, Paidós.

BERLIN, I. (1992): El fuste torcido de la humanidad, Barcelona, Península.

BERMAN, M. (1988): Todo lo sólido se desvanece en el aire, Madrid, Siglo XXI.

BURGUIÈRE, A. et al. (1988): Historia de la familia, Vol. 2, Alianza, Madrid.

CASTAÑEDA, C. (2000): «Globalización», El País, miércoles I de marzo, pp. 17 18.

CASTELLS, M. (1997): La era de la información. La sociedad red, Madrid, Alianza. 
CASTELLS, M. (1998a): La era de la información. El poder de la identidad, Madrid, Alianza.

CASTELLS, M. (1998b): La era de la información. Fin de milenio, Madrid, Alianza.

ESTEFANÍA, J. (2000): Aquí no puede ocurrir, Madrid Taurus.

GIDDENS, A. (1999): La tercera vía, Madrid, Taurus.

GIDDENS, A. (2000): Un mundo desbocado. Los efectos de la globalización en nuestras vidas, Madrid, Taurus.

GÓMEZ, L. (1999): «Cuatro millones de niños malviven bajo condiciones de pobreza en el Reino Unido», EI País, miércoles 21 de julio, p. 24.

HIRSCHMAN, A. O. (1991): Retóricas de la intransigencia, México, F.C.E.

HOBSBAWM, E. (2000): Entrevista sobre el siglo XXI, Barcelona, Crítica.

MAYOR ZARAGOZA, F. (2000): «La educación para todos, el gran reto del siglo XXI», El País, lunes 24 de abril de 2000, pp. 15-16.

MAYORZARAGOZA, F; BINDÉ, J. (1999): «Siglo XXI: ¿un mundo mejor o un mundo feliz?», El País, viernes 22 de octubre de 1999, pp. 15-16.

NAVARRO, V. (1997): Neoliberalismo y Estado del Bienestar, Barcelona, Ariel.

NAVARRO, V. (1999): «Calidad de vida y desigualdad social», El País, viernes 3 de septiembre, pp. 13-14.

NÚÑEZ, C. E. Y TORTELLA, G. (eds) (1993): La maldición divina. Ignorancia y atraso económico en una perspectiva histórica, Madrid, Alianza.

OIT (1996): Child labour: targetig the intolerance, Ginebra.

PNUD (1998): Informe sobre desarrollo humano 1998.

PNUD (1999): Informe sobre desarrollo humano 1999.

POLANYI, K. (1989): La gran transformación, Madrid, Ediciones La Piqueta. PRIGOGINE, I. (1997a): Las leyes del caos, Barcelona, Crítica.

PRIGOGINE, I. (1997b): El fin de las certidumbres, Madrid, Taurus.

SARTORI, G. (1998): Homo videns, Madrid, Taurus.

SEDKY-LAVANDERO, J. (1999): Ni un solo niño en la guerra. Infancia y conflictos armados, Barcelona, Icaria.

SEN, A. (1995): Nuevo examen de la desigualdad, Madrid, Alianza.

STRANGE, S. (2000): Dinero loco. El descontrol del sistema financiero global, Barcelona, Paidós.

THERBORN, G. (1993): «Los derechos de los niños desde la constitución del concepto moderno de menor: un estudio comparado de los países occidentales», en Moreno L.(comp.), Intercambio social y desarrollo del bienestar, Madrid, CIS.

TORTOSA, J.M. (1992): Sociología del sistema mundial, Madrid, Tecnos. 
TORTOSA, J.M. (1993): La pobreza capitalista, Madrid, Tecnos.

TORTOSA, J.M. (2000): El juego global: pobreza, desarrollo, prospectiva, Barcelona, Icaria.

TOWSEND, P. (1993): The international analysis of poverty, Londres, Harvester Wheatsheaf.

UNICEF (1999a): El progreso de las naciones.

UNICEF (1999b): Estado mundial de la infancia. Educación.

UNICEF (2000): Violencia doméstica. Una epidemia global.

VV. AA. (1996): Declaración de Beijing y plataforma para la acción, Madrid, Ministerio de Asuntos Sociales, Instituto de la Mujer.

VV. AA. (1998): Beyond the threshold. The measurement and analiysis of social exclusion, G. Room (ed.), Bristol, Policy Press.

VERDÚ, V. (1996): El planeta americano, Barcelona, Anagrama.

WALLERSTEIN, I. (1988): El capitalismo histórico, Madrid, Siglo XXI.

WALLERSTEIN, I. (1997): El futuro de la civilización capitalista, Barcelona, Icaria.

WALLERSTEIN, I. (1999): Utopística, México, Siglo XXI.

WALLERSTEIN, I. (2000): «El eurocentrismo y sus avatares: los dilemas de las ciencias sociales», New Left Review 0, pp. 97-113. 